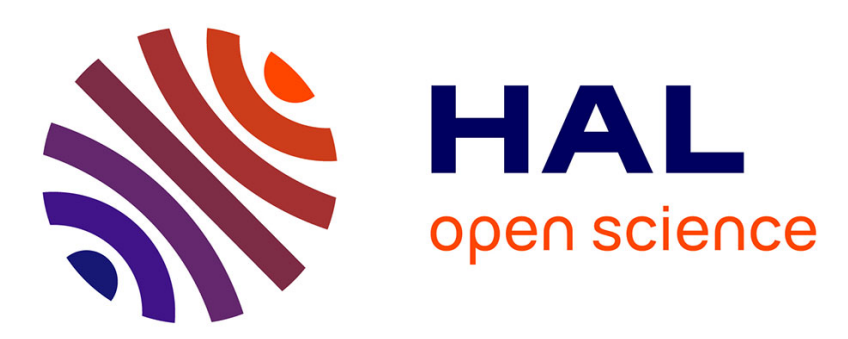

\title{
Investigation of tool failure modes and machining disturbances using monitoring signals
}

Andreï Popa, Gilles Dessein, Maher Baili, Vincent Dutilh

\section{To cite this version:}

Andreï Popa, Gilles Dessein, Maher Baili, Vincent Dutilh. Investigation of tool failure modes and machining disturbances using monitoring signals. Advanced Materials Research, 2012, vol. 423, pp. 128-142. 10.4028/www.scientific.net/AMR.423.128 . hal-00854452

\section{HAL Id: hal-00854452 \\ https://hal.science/hal-00854452}

Submitted on 27 Aug 2013

HAL is a multi-disciplinary open access archive for the deposit and dissemination of scientific research documents, whether they are published or not. The documents may come from teaching and research institutions in France or abroad, or from public or private research centers.
L'archive ouverte pluridisciplinaire HAL, est destinée au dépôt et à la diffusion de documents scientifiques de niveau recherche, publiés ou non, émanant des établissements d'enseignement et de recherche français ou étrangers, des laboratoires publics ou privés. 


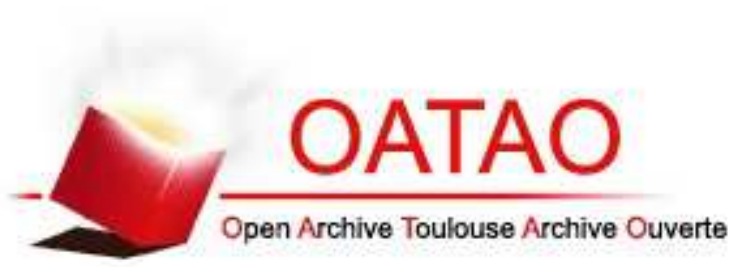

\section{Open Archive Toulouse Archive Ouverte (OATAO)}

OATAO is an open access repository that collects the work of Toulouse researchers and makes it freely available over the web where possible.

This is an author-deposited version published in: http://oatao.univ-toulouse.fr/ Eprints ID: 6526

To link to this article: DOI:10.4028/www.scientific.net/AMR.423.128 http://www.scientific.net/AMR.423.128

\section{To cite this version:}

Popa, Andreï and Dessein, Gilles and Baili, Maher and Dutilh, Vincent Investigation of tool failure modes and machining disturbances using monitoring signals. (2021) Advanced Materials Research, vol. 423 .pp. 128142. ISSN 1022-6680

Any correspondence concerning this service should be sent to the repository administrator: staff-oatao@inp-toulouse.fr 


\title{
Investigation of tool failure modes and machining disturbances using monitoring signals
}

\author{
Andrei Popa ${ }^{1, a}$, Gilles Dessein ${ }^{1, b}$, Maher Baili ${ }^{1, c}$ and Vincent Dutilh ${ }^{2, d}$ \\ ${ }^{1}$ Université de Toulouse, INPT- ENIT, Laboratoire Génie de Production - 47 avenue \\ d'Azereix - 65016 Tarbes, France \\ 2 Turbomeca Bordes, 64511 Bordes Cedex, France \\ a andrei.popa@enit.fr, b gilles.dessein@enit.fr, cmaher.baili@enit.fr \\ d vincent.dutilh@turbomeca.fr
}

Keywords: Drilling, nickel base superalloy, monitoring, wear.

\begin{abstract}
The ACCENT Project (FP7- AAT- 2007- RTD-1) will allow the European Aero Engine manufacturers to improve their competitiveness by applying adaptive control techniques to the manufacturing of their components. For the critical rotating parts of aircraft engines, the surface integrity generated after machining is a key factor on the life cycle. In this context, one particular attention has to be carried out on tool condition. The aim of this paper is to define a monitoring approach able to detect the tool condition and machining disturbances. The main failure modes characterizing this particular Nickel base drilling and the apparition of embedded chips over the machined surface were identified. By experimental techniques, cartography of failure modes was performed. The results show that flank wear and notch are the main failure modes limiting the tool life. For some cutting conditions, the tool failure occurs after the first hole due to the important cutting forces. Some interesting combinations are made between the spindle current/accelerometers/ thrust force and flank wear, tool breakage and notch. Before these correlations, a detailed signal analysis was performed, considering different disturbing phenomena, such as chips evacuation problem. Finally, a "synopsis" for process monitoring is proposed, considering the analyzed phenomena.
\end{abstract}

\section{Introduction}

The superalloys can be classified in three categories: Nickel base, Iron base and Cobalt base. In the aircraft industry, the Nickel base superalloys are often used for the applications at high temperature, such as turbine discs. The Udimet ${ }^{\circledR} 720$ has replaced the Inconel 718 due to its higher mechanical properties at high temperatures and other advantages in terms of corrosion resistance. However, their properties, the tool life and anomalies which may occur during the machining, make the Nickel base superalloys "difficult-to-cut" [1]. The choice of cutting parameters (cutting speed, feedrate, percentage of emulsion in cutting fluid, etc), the low thermal conductivity which characterize these materials, the chemical affinity for tool materials, the tool geometry and the coating type are essential factors on the tool life.

A tool geometry variation (i.e. built-up edge, chipping, excessive wear or tool failure) during drilling can lead to surface integrity problems (roughness profile deviation, thermo-mechanically affected layer, etc.). For the critical parts, it is important to prevent these anomalies. All these appreciations make the tool wear a key factor for the quality of produced parts.

Sharman [2] shows the influence of the geometry and type of coating on the tool life in drilling of Inconel 718. In this study, the drills having a curved edge and radius on the periphery had a higher performance comparing to drills with either a straight or concave cutting edge or sharp periphery. In the same direction, for turning of Inconel 718 without lubricant, Devillez [3] shows the influence of coating type. Several coatings were evaluated on different cutting speed, chosen between 20 and $200 \mathrm{~m} / \mathrm{min}$ and feederate 0.1 and $0.2 \mathrm{~mm} / \mathrm{rev}$. The best coated type was used for a bar turning operation. During these tests, the principal wear modes were welding, adhesion of workpiece material onto the tool and abrasion flank wear. Chen [4] studied the wear mechanisms in drilling Inconel 718 with multi-layer TiAlN PVD coated tungsten carbide twist drills. Selected cutting 
speed was $13.2 \mathrm{~m} / \mathrm{min}$ and feedrate was $0.1 \mathrm{~mm} / \mathrm{rev}$. The authors explained the wear evolution by dividing into four steps. At the first phase, due to the friction force, the coated layer is removed. The next period is represented by the apparition of flank wear and chipping. For the third stage, micro cracks appear in the chipping region. Finally, corroborating with crater wear causes the drill failure. In order to facilitate and secure the validation process of a produced piece or just to monitor the tool condition, intensive researches are focused on process monitoring, and more precisely by using physical measurements as non-destructive control. Generally, two methods (direct and indirect) can be applied. Most of direct methods (e.g. cameras for visual inspection or laser beams) can be used only as laboratories technics (even they have a high accuracy), due to some limitations in industry, such as use of cutting fluid, low light, etc. Indirect methods are based on physical quantities, such as cutting forces, power and temperature. They are more suitable for industrial applications. A large number of papers deal with Tool Condition Monitoring (TCM). Jantunen [5] presents the main monitoring technics and signal analyses available in the literature. Statistical parameters (mean value, maximum value, kurtosis, skewness, etc.), frequency analysis of signals are used in order to monitor the tool condition.

The power signal recorded during the machining is compared by Axinte [6] with force and torque signals in order to verify the sensitivity of this physical quantity in tool condition monitoring. In continuous machining processes, i.e. turning and drilling, the power can be considered appropriate to detect both chipping and gradual tool wear. On other hand, for the intermittent processes (milling) the power is not sensitive enough to identify a chipped cutter. This can be attributed to the fact that this signal lost the intermittent "sow teeth" patterns, that's allowed to detect eventual events. In fine milling of Inconel 718, Debard [12] use cutting conditions to fit a model for the measured efforts. Further, this model is used for a tool wear phenomenological model.

The vibration signal is often used as source of information about the process. In drilling of high speed steel C 1040, Abu-Mahfouz [7] uses features extracted by vibration signal as input parameters in neural network for prediction and classification of wear (chisel wear, crater wear, flank wear, edge fracture). The neural networks are also used by D'Addona [13] in turning of Inconel 718 to predict the tool wear. Using the feedrate and the machining time as input layer, they obtained promising results.

\section{Experiments}

Drilling tests were carried out on $\varnothing 80 \mathrm{~mm}$ forged bars, usually used as raw material in turbine discs manufacturing. These bars have the same heat treatments as the discs (solution Heat Treatment and aged) in order to obtain the nearest routine mechanical properties to the original discs (same microstructure, same grain size $\geq 8$ (ASTM) and same Hardness $H V \geq 410$ HV30).

The tool is a $\varnothing 15.5 \mathrm{~mm}$ drill Iscar Chamdrill with an interchangeable TiAlN coated carbide head. This drill has the particularity of having a very short margin $(4 \mathrm{~mm})$, which avoids anomalies generated by friction all along the hole.

The operation is a drilling in a pre-hole $\varnothing 13 \mathrm{~mm}$. The length of the hole is $37 \mathrm{~mm}$.

All tests were made in a HURON KX10 3-axis vertical milling center using an 18kW spindle motor and a Siemens $840 \mathrm{D}$ numerical controller. The lubrication is made at tool center and the cutting fluid pressure was fixed at 17 bars.

The machine-tool was instrumented with a 4 component Kistler dynamometer (Fx, Fy, Fz and Mz), type 9272A. Signals are conditioned with an amplifier type 5019A and processed using Dynoware software. The dynamometer has a large measurement range in amplitude (up to $20 \mathrm{kN}$ for the thrust force $\mathrm{Fz}$ and $200 \mathrm{Nm}$ for the torque). The natural frequencies given by Kistler are: $f_{n}(x, y)-3.1$ $\mathrm{KHz} ; \mathrm{f}_{\mathrm{n}}(\mathrm{z})-6.3 \mathrm{KHz} ; \mathrm{f}_{\mathrm{n}}\left(\mathrm{M}_{\mathrm{z}}\right)-4.2 \mathrm{KHz}$.

Vibrations measurements are performed with uniaxial accelerometers Brüel \& Kjær Type 4508. The conditioner consists of an input-output module and a network module Brüel \& Kjær Type 3109 and 7533. The data are recorded and processed using software Brüel \& Kjær Pulse®. The measuring range of the accelerometers is from $1 \mathrm{~Hz}$ to $8 \mathrm{kHz}$ frequency and $\pm 700 \mathrm{~ms}^{-2}$ accelerations. 
Spindle power, position in $\mathrm{Z}$ axis, spindle current intensity and current intensity of the three axes are recorded through Siemens Profibus.

A special device was designed for these tests and it is presented in the Figure 1. This set-up permits to drill 6 holes on each sample, ensuring that each test is not influencing by others. All the work done in this paper is a part of European Project ACCENT (Adaptive Control of Manufacturing Processes for a New Generation of Jet Engine Components).

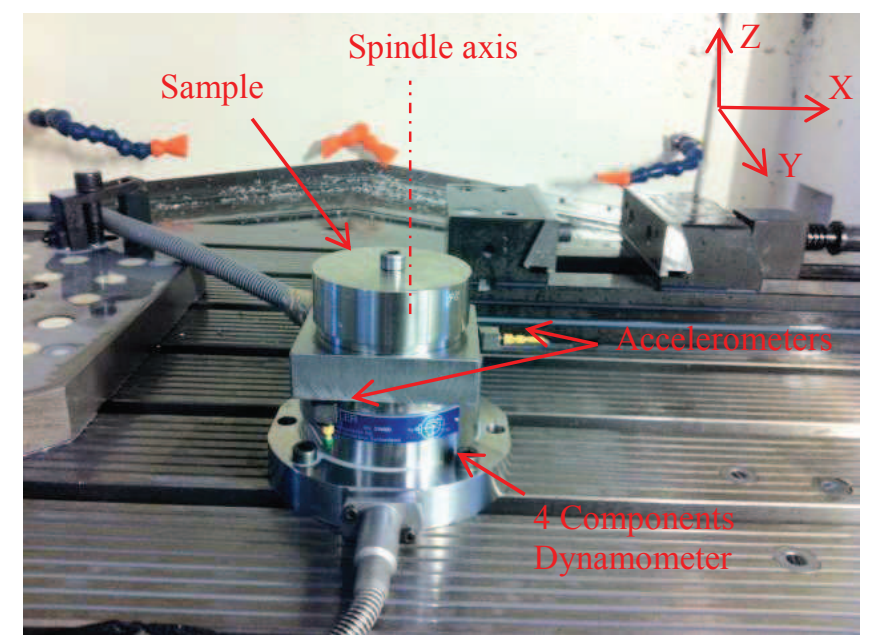

Figure 1.Experimental set-up and monitoring sensors

The main objective of this project is to reduce the uncertainty in manufacturing by using Process Monitoring. Several experimental campaigns were implemented:

1. Combining the cutting conditions according to classic criteria established by the French specification AFNOR E66-520 (Couple-Tool-Material) to find the optimal cutting speed and feedrate [9].

2. The main criterion of Couple-Tool-Material is the specific cutting energy. But, in order to define a window that insures the surface integrity obtained after machining, this criterion is not enough. For this reason, new operating points were tested and analyzed using surface integrity criteria (roughness, thermo-mechanically affected layer, residual stresses, etc.) in order to define an Acceptable Surface Integrity Domain.

3. Machining disturbances (corresponding to tool position defect, cutting fluid emulsion variation or changes of the material hardness) were tested to understand their impact on surface integrity and signals [10].

4. The purpose of the last campaign was to understand the wear behavior for this combination process-material and possible machining disturbances. Based on "Cartography" tests results, several cutting conditions were chosen to drill more than just one hole with the same tool. All the tested points will be described in chapter 3 .

\section{Results}

Results of drilling tests performed in Udimet $720^{\circledR}$ are presented in terms of failure modes and evolution of physical measurements. After each test, images of the tool were taken with a binocular. For the notch, only the surface was considered in this study (as illustrated in the Figure 4b).

\subsection{Evolution of failure modes}

\subsubsection{Tool flank wear}

The first wear type identified is the flank wear. The coated layer is abraded-off, due to the friction force. As shown on Figure 2a, two zones are delimited. The first one corresponds to cutting speeds lower than $20 \mathrm{~m} / \mathrm{min}$ and feedrates $0.1 \mathrm{~mm} / \mathrm{rev}$ and $0.25 \mathrm{~mm} / \mathrm{rev}$. The black circles represent the cutting conditions chosen to drill several holes with the same tool (in production the tool life is 
limited at 2 holes). Finally were performed 5 holes for $\mathrm{Vc}=10 \mathrm{~m} / \mathrm{min}$ and 3 holes for the other two points. The results of these tests (Figure 3a) show a slow increase in terms of flank wear, between $0.05 \mathrm{~mm}$ and $0.13 \mathrm{~mm}$ (the uncertainty is $0.01 \mathrm{~mm}$ ).

Regarding the second zone (Figure 2), the tool behavior is different. After the first machining, the tool is presenting just flank wear. Contrary to the first zone, for the second test, it can be seen that immediately after the entrance in the material, the tool breakage occurs. This behavior is relatively close to one observed by Rancic [14], during titanium turning. By comparing the results of continuous tests with divided tests, the author highlights the major role of the entrance and leaving in the material for the tool integrity. This conclusion is consistent with the results obtained for the second zone. Figure $3 \mathrm{~b}$ presents a comparison between drillings at low and high cutting speeds, only for flank wear values obtained after the first test. For the first zone, it seems that the flank wear is increasing with the cutting speed. For the second zone, this tendency is not so obvious.

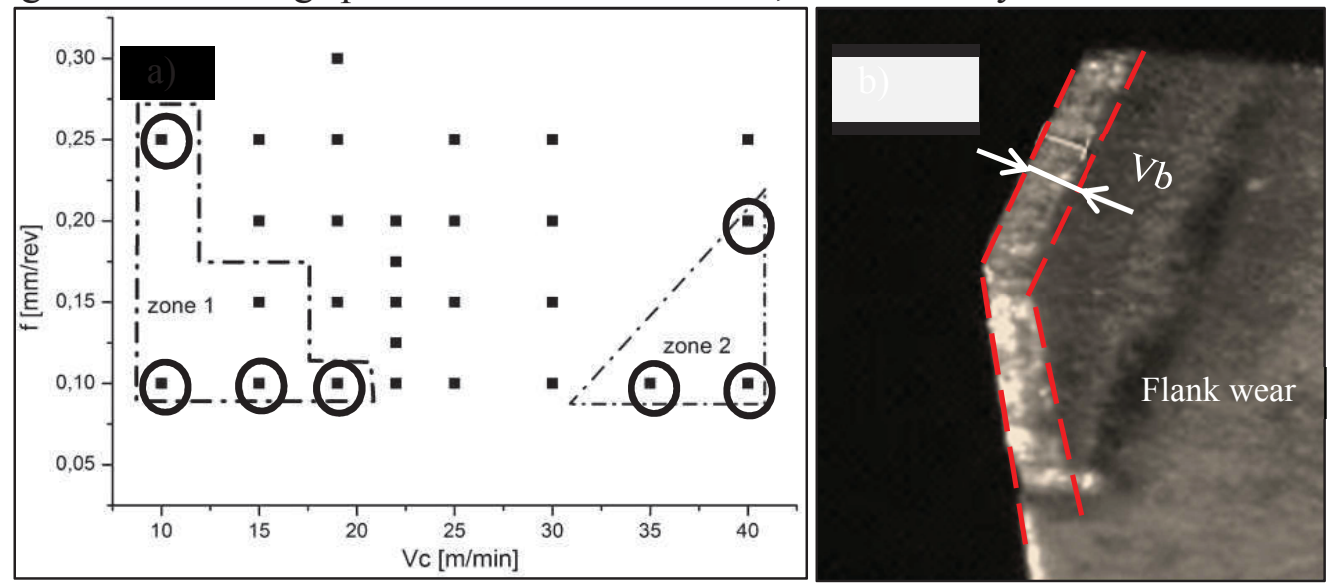

Figure 2. Flank wear
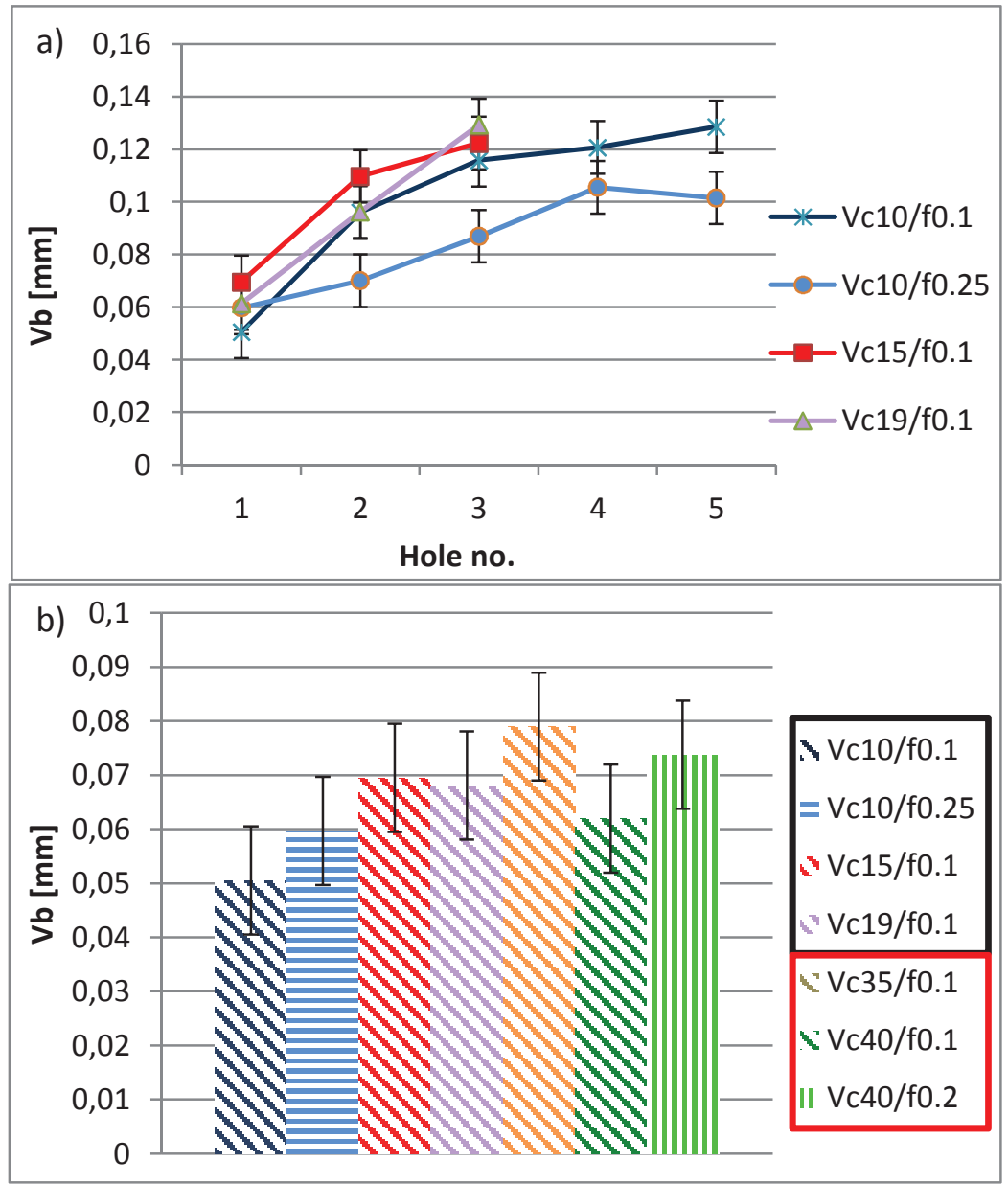

Figure 3. Flank wear evolution 


\subsubsection{Notch}

Due to specificity of the process (drilling in a pre-hole) another failure mode observed is the notch wear (Figure 4b). The notch apparition is explained by the difference of pressure at the limit of cutting zone [15]. Figure 4a presents the second zone proposed in this study, characterized by flank wear and notch.

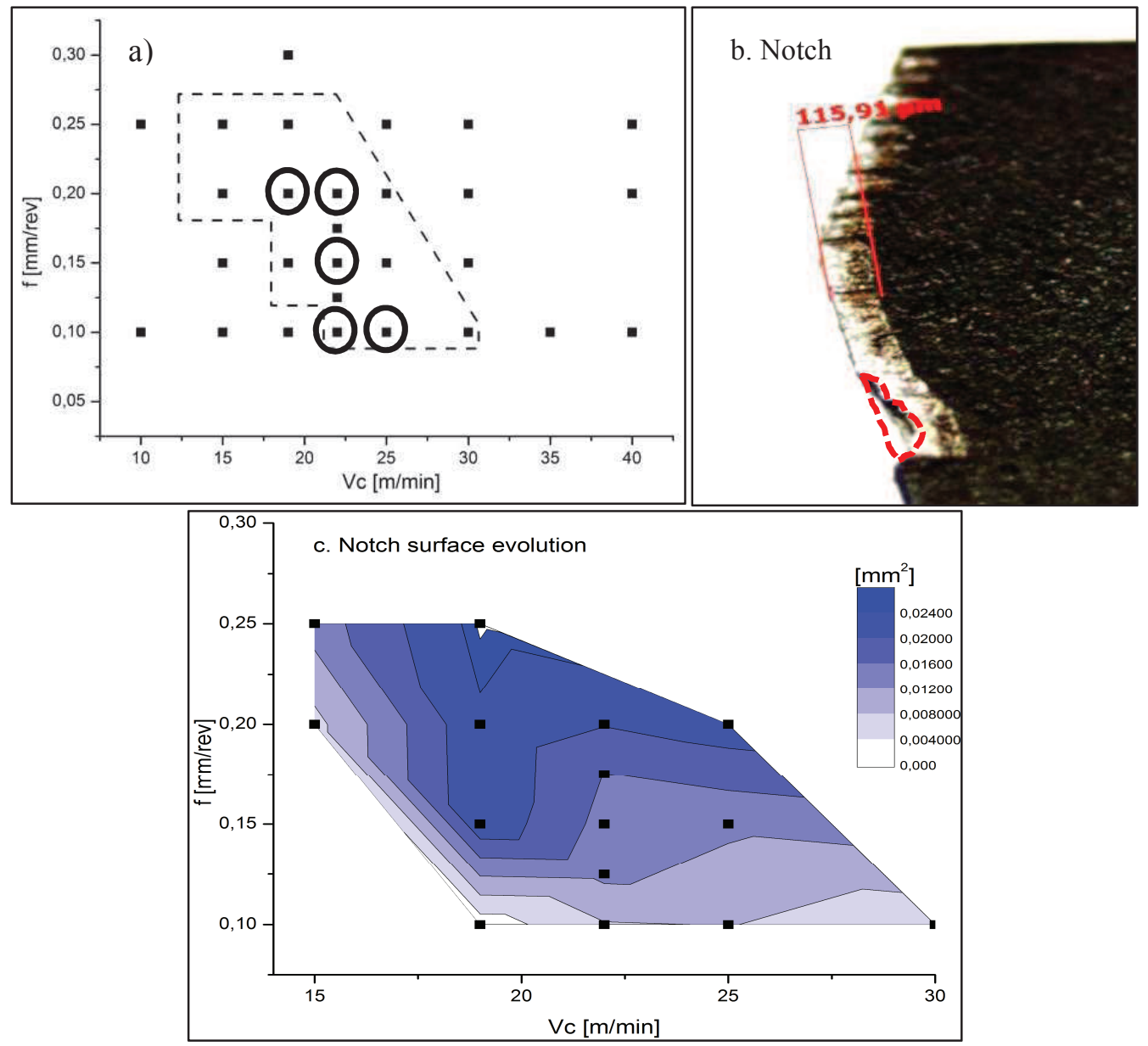

Figure 4. a). Notch domain; b). Example; c). Evolution after the first machining

The flank wear evolution follows the same pattern as before. A slow increase could be observed for tests having a low feedrate. For cutting speed $\mathrm{Vc}=19 \mathrm{~m} / \mathrm{min}$ and feedrate $0.2 \mathrm{~mm} / \mathrm{rev}$ the increasing is more emphasized (more than $50 \%$ between 2 holes). At $25 \mathrm{~m} / \mathrm{min}$, the results are more interesting. After the first hole, the wear level is about $0.05 \mathrm{~mm}$ and is increasing until $0.18 \mathrm{~mm}$ for the second test. Further, the tool breakage occurs.

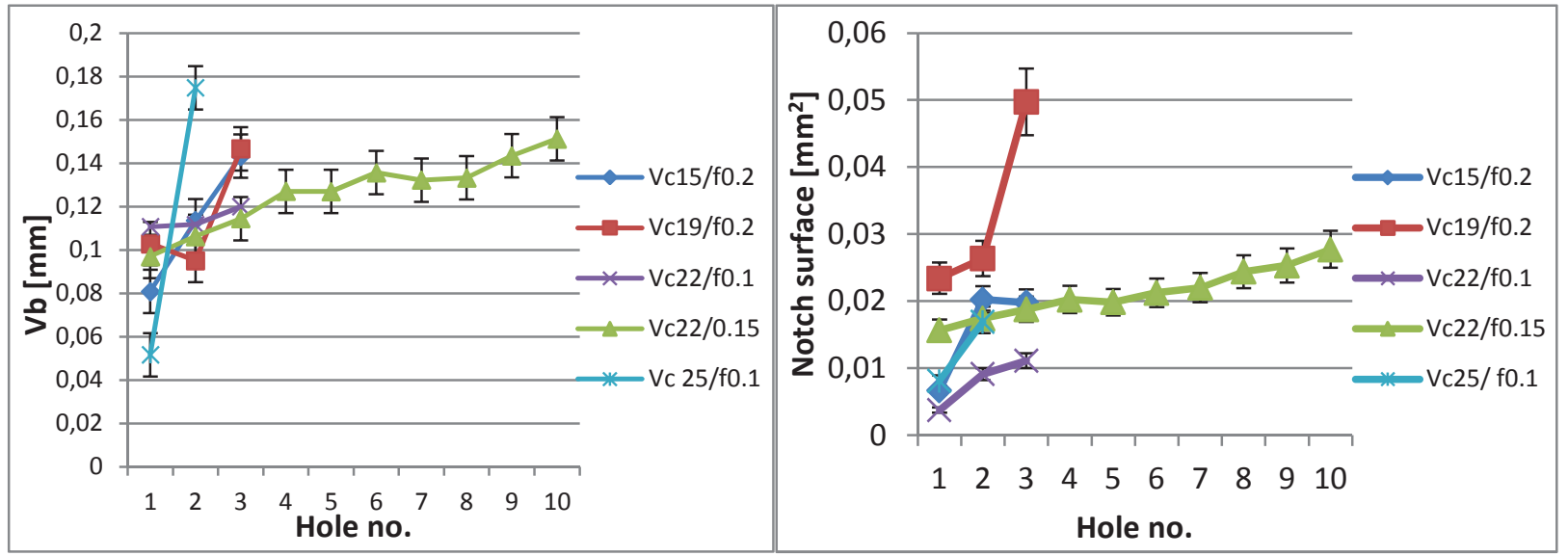

Figure 5. Flank wear and notch evolution 
For one cutting condition, $\mathrm{Vc}=22 \mathrm{~m} / \mathrm{min}$ and $\mathrm{f}=0.15 \mathrm{~mm} / \mathrm{rev}$ were performed 10 tests with the same tool. It seems that the tool honing is done after the first hole and further the wear is slowly increasing (between 0.1 and $0.15 \mathrm{~mm}$ ).

The notch evolution after the first hole is presented in the Figure 4c. It is obvious that at higher feedrates, the notch dimensions are increasing.

\subsubsection{Tool breakage}

The third zone is differentiating by catastrophic wear. Once the cutting forces become too important, the notch surface is increasing until the tool breakage occurs. The collapse of the cutting edge is made between the limit of the cutting zone and the clearance face.
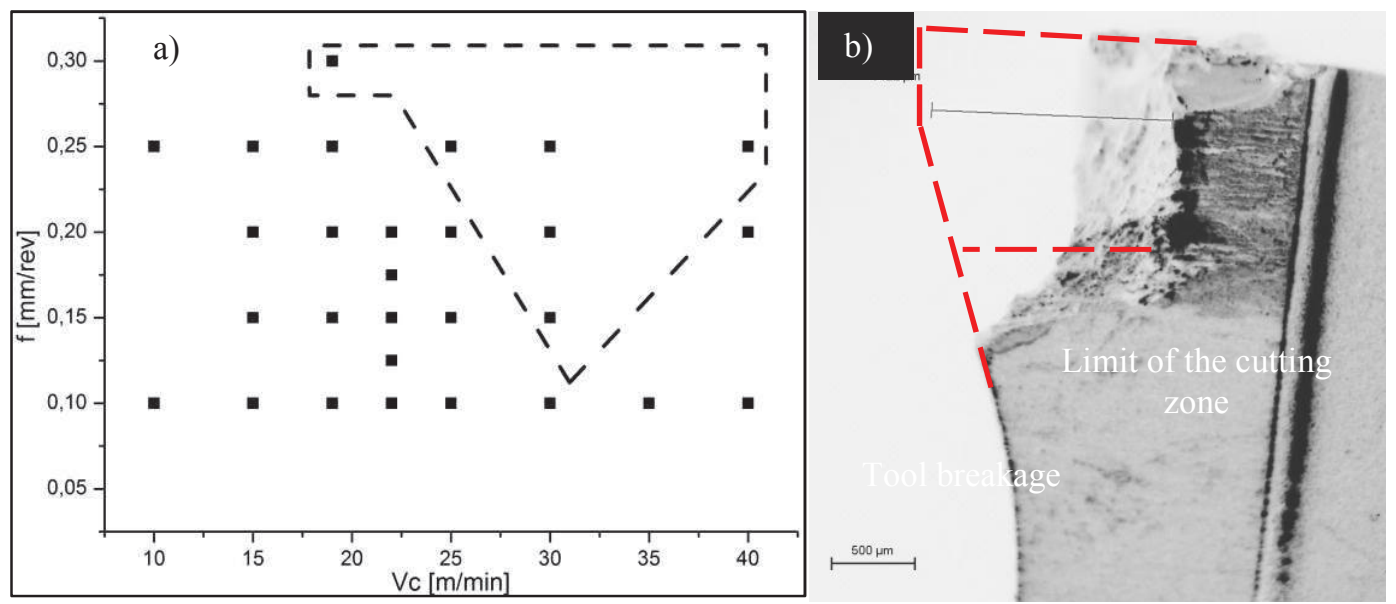

Figure 6. a).Tool breakage domain ; b). Example

Figure $6 \mathrm{~b}$ illustrates an image with tool breakage. It's the consequence of the most severe cutting conditions, $\mathrm{Vc}=40 \mathrm{~m} / \mathrm{min}$ and $\mathrm{f}=0.25 \mathrm{~mm} / \mathrm{rev}$. The same results were obtained for the others points tested.

\subsubsection{Tool damage area}

Figure 7 presents the cartography of failure modes obtained by gathering all together the results presented in the chapter 3 . The failure modes obtained for this process are closely related to the machining context (drilling in a before hole, from $\Phi 13 \mathrm{~mm}$ to $\Phi 15.5 \mathrm{~mm}$ - influence on the difference of pressure at the limit of the cutting zone). The window distribution is obtained according to the failure modes found for this process and will be necessary a tool condition monitoring for each one. Really interesting is the apparition of flank wear at high cutting speeds and this information can be a point for future analysis.

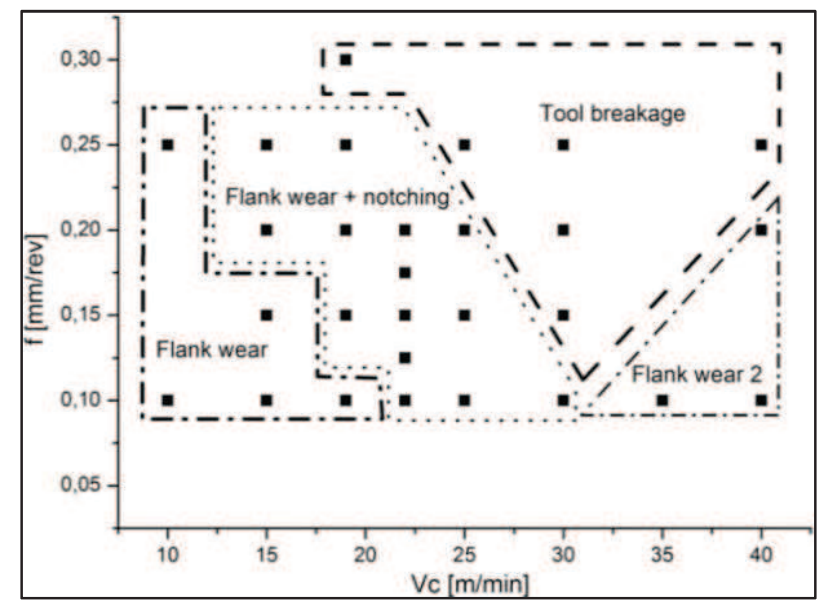

Figure 7. Cartography of failure modes 


\section{Signals evolution}

The first part of this work highlights the tool behavior over a wide range of cutting conditions. In this section, the signals will be analyzed in order to verify which one is more suitable for tool condition monitoring.

Regarding the accelerometer signals, it has to be mentioned that frequency identification was performed before all analysis. Three different tests were applied in order to identify the natural frequencies of machining system (spindle + tool holder + tool):

- Hammer test

- Tests without Kistler dynamometer.

- Finite element analysis (tool holder + tool)

The final results are presented in Table 1:

Table 1. Natural frequencies of the system/dynamometer and the main vibration directions

\begin{tabular}{|c|c|c|}
\hline Frequency $[\mathrm{Hz}]$ & Vibration mode & \\
\hline 700 & Mode 1 system & \multirow{7}{*}{$\begin{array}{l}\text { Blue } \\
\text { direction }\end{array}$} \\
\hline$\sim 1000$ & Kistler dynamometer $-\mathrm{f}_{\mathrm{n}}(\mathrm{x}, \mathrm{y})$ & \\
\hline 1320 & Mode 2 system & \\
\hline 1560 & Mode 3 system & \\
\hline 1900 & Mode 4 system & \\
\hline 2176 & Kistler dynamometer $-\mathrm{f}_{\mathrm{n}}\left(\mathrm{M}_{\mathrm{z}}\right)$ & \\
\hline$\sim 6000$ & Kistler dynamometer (z) & \\
\hline
\end{tabular}

The red direction corresponds to the displacement direction of vibration mode for the second and the fourth vibration mode of the system. The third vibration mode has a direction (blue line) perpendicular to the other two modes.

In turning, Bisu [16] indicates the privileged directions of the movement associated with the maximum and minimum stiffness. When the tool is vibrating, due to the different damping and stiffness along the two axes (the tool being asymmetric), the movement of tool center describes an ellipse. For the tests presented in this work, the spindle speed is considered low and it could be estimated that the tool is in quasi-static case. Taking into account these considerations, it can be admitted that the cutting process may excite two perpendicular directions. According to different kind of stresses, the drill will vibrate on these directions. This justification will be applied for the drill and several cases will be further detailed. The results from accelerometers will be presented as time-frequency diagram, obtained using Short Time Fourier Transform (STFT).

\subsection{Flank wear}

\subsubsection{Zone 1}

The Figure 8 presents the characteristic signals for tests having just flank wear in zone 1 (Figure 2a). The cutting conditions are $\mathrm{Vc}=19 \mathrm{~m} / \mathrm{min}$ and feedrate $=0.1 \mathrm{~mm} / \mathrm{rev}$. At the end of the drilling, the flank wear is about $0.056 \mathrm{~mm}$. The signals extracted from the Kistler dynamometer are presented in the Figure $8 \mathrm{~b}$ and $8 \mathrm{~d}$. They are filtered with a $30 \mathrm{~Hz}$ low pass filter, corresponding to 3 times the tooth frequency. The filtered torque $\mathrm{Mz}$ has the same typology as the spindle current. The first stage of a drilling, the entrance of tool in material, can be identified using all signals. It corresponds to the first 9 seconds. In this stage, the tool is not guided by the two margins making 
possible all displacements. For this reason more frequencies can appear as presented in the timefrequency diagram (Figure 8c). Here, can be identified the second natural frequency of the system $(1320 \mathrm{~Hz})$, one peak around $1000 \mathrm{~Hz}$ corresponding to Kistler dynamometer and the corresponding harmonics. When the machining is stable, after $9 \mathrm{~s}$, the spindle current has a constant evolution, around 5A. Regarding the frequencies, only the fourth natural mode of system can be found $(\sim 1950$ $\mathrm{Hz})$ and the corresponding harmonics. The spindle current is increasing during the machining on 4 peaks. This interesting phenomenon cannot be associate to a tool problem (flank wear, notch or tool breakage) because after these peaks, the spindle current level has the same value as before. One hypothesis can be a chips evacuation problem. Two possibilities can be accepted in this way. The first one, during drilling, the chips are fragmented and it's possible that very thin chips can be stuck between the tool and the piece. The second one considers that due to a bad fragmentation, the chips form long part. Again, the result may be a chip stuck between the tool and the workpiece, but this time with a higher impact on the signals. The phenomenon presents a major interest in this machining context due to the direct impact on the surface integrity. Another work done in the same context (materials, cutting conditions, etc.) conducted for the first experimental campaign (COM) by Dutilh [9], show that the consequence is a low roughness profile and the existence of embedded chips. Also, the authors correlate the roughness profile with the power consumption. This hypothesis is strengthened by a closer analysis of accelerometers. Figure 9 presents the frequency evolution during the peak of spindle current (red rectangle Figure 8a). The first FFT (Figure 9a) shows the fourth mode of the system which characterize a stable machining (around $2000 \mathrm{~Hz}$, but it varies between $1950 \mathrm{~Hz}$ and $2028 \mathrm{~Hz}$ ) and its harmonics. Further, when the chip comes stuck between the margins and the workpiece, a small shock will be generated. In this case, a major effort is generated with the resultant along red direction. and the second mode $(1320 \mathrm{~Hz})$ of the system is excited and also the first mode of Kistler dynamometer $(\sim 1000 \mathrm{~Hz})$. Once the chip is evacuated, the frequency evolution comes back as before (Figure 9c). During the machining, the frequency at 1950 $\mathrm{Hz}$ evolves until $2040 \mathrm{~Hz}$ (Figure 9a and 9c). Generally, the frequencies evolve due to different factors, such as stiffness, wear and contact nature between the tool and workpiece.

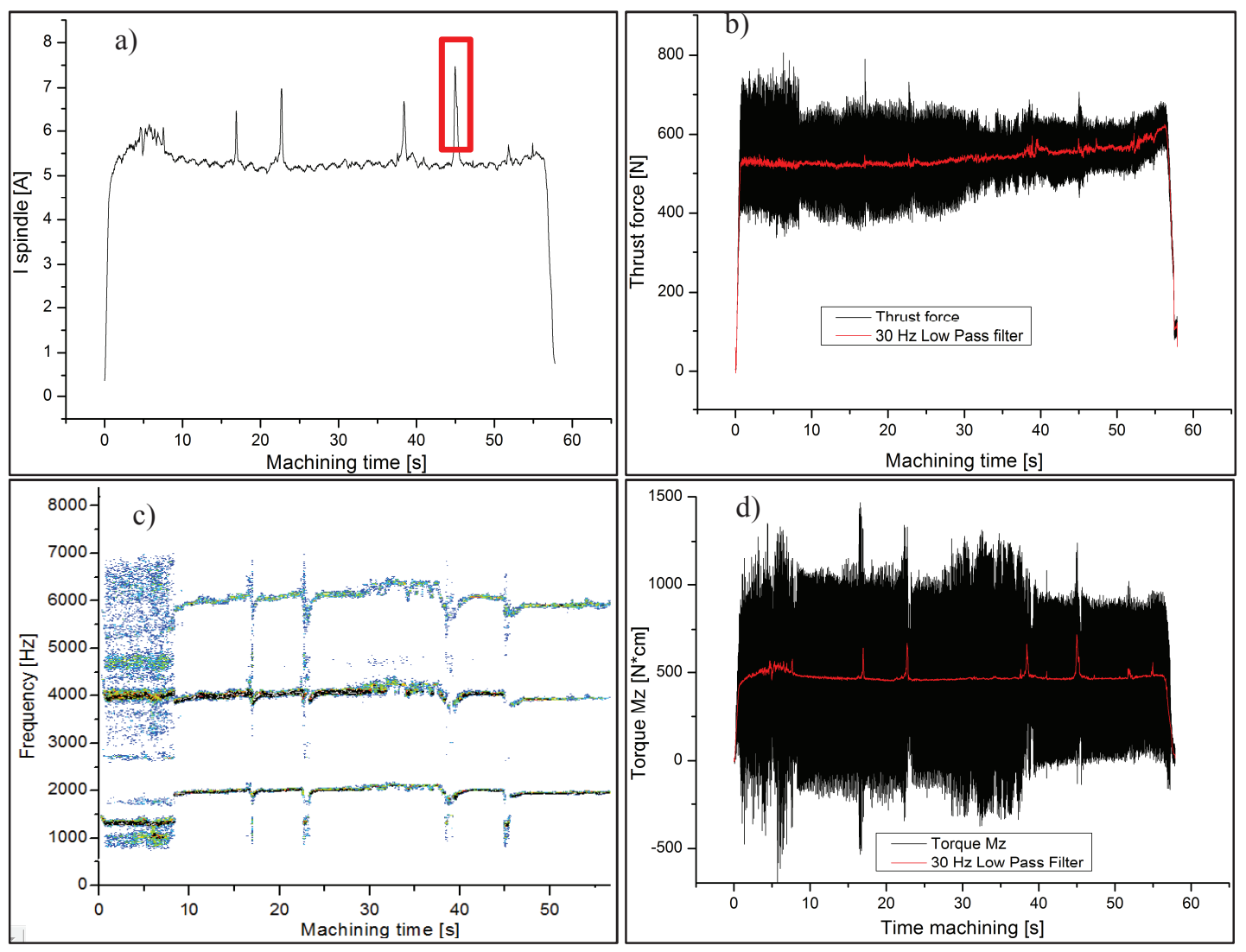

Figure 8. a) I spindle; b) Thrust force; c) Time-frequency diagram; d) Torque Mz 

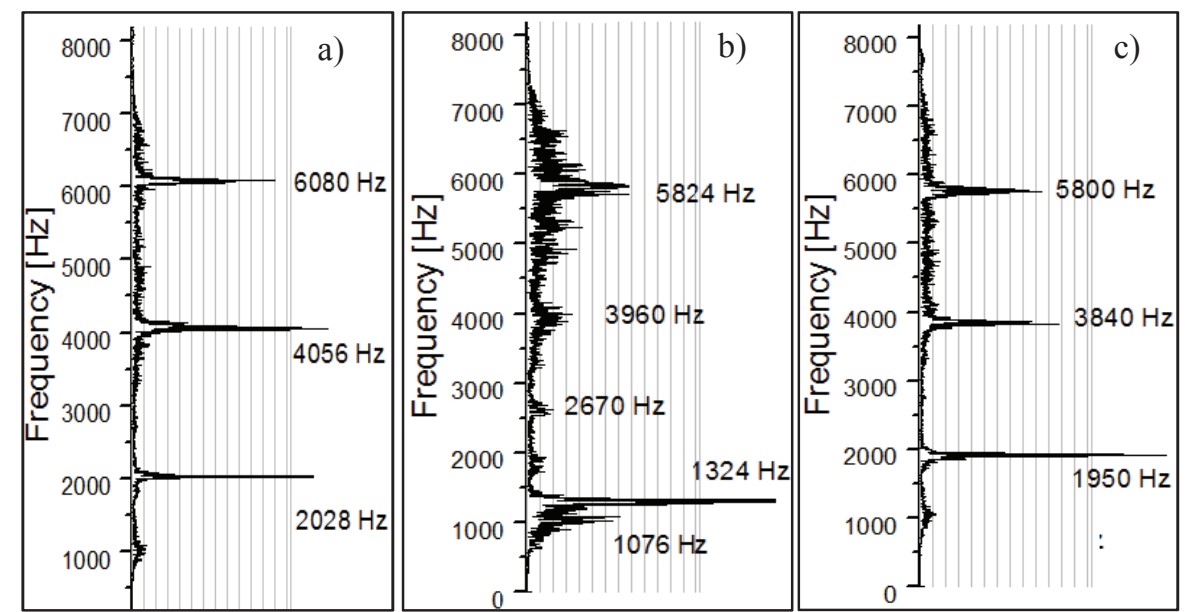

Figure 9. Frequency evolution during a chips evacuation problem: a) before; b) during; c) after

The example presented in chapter 4.1.1 shows the "typical signals" for a stable machining, isolating chips evacuation problems. Further, another example will illustrate the evolution of signals when the $\mathrm{Vb}$ is increasing more than $0.06 \mathrm{~mm}$. Figure 10 presents the spindle current evolution (a), the torque (c) and the time-frequency diagram for the cutting conditions $\mathrm{Vc}=15 \mathrm{~m} / \mathrm{min}$ and $\mathrm{f}=0.1$ $\mathrm{mm} / \mathrm{rev}$. At the end of test, the $\mathrm{Vb}$ is around $0.075 \mathrm{~mm}$.
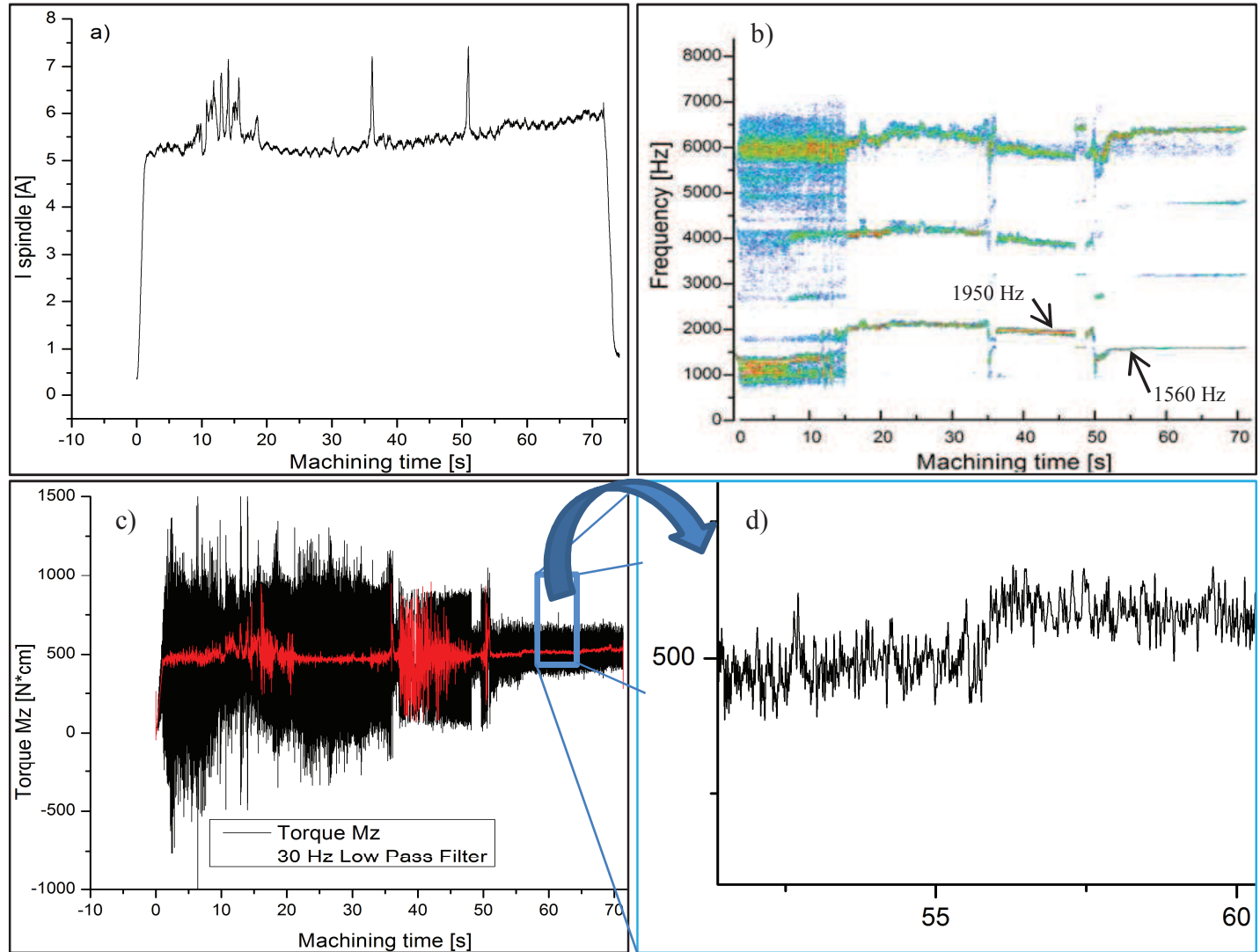

Figure 10. a) I spindle; b) Time-frequency diagram; c) Torque Mz; d) Zoom on Torque signal

The following considerations can be done:

- The drilling is characterized by a constant level of power consumption and frequency evolution (fourth natural frequency $-1950 \mathrm{~Hz}$ );

- The phenomenon of the chips evacuation problem can be observed on the signals.

- One observation can be made for the drilling after 50 seconds. The time-frequency diagram (Figure 10b) shows a sudden decrease, from $1950 \mathrm{~Hz}$ to $1560 \mathrm{~Hz}$. Together with the small increase of the torque (around 5\% - Figure 10d), this event may be 
explained by flank wear. Once the $\mathrm{Vb}$ is increasing, the surface contact and the friction are also increasing. The third natural mode $(1560 \mathrm{~Hz})$ has the displacement direction of vibration mode perpendicular to the cutting zone and his apparition is connected with the increasing wear. This observation was done for several tests inside zone 1 (Figure 2a).

\subsubsection{Zone 2}

The flank wear was found also in the second zone, at high cutting speeds. One example is chosen to illustrate the main difference between these two zones, in terms of process monitoring. Even the wear level is quite similar, some differences exists. Figure 11 presents the evolution of spindle current and the FFT diagram obtained for the cutting conditions $\mathrm{Vc}=40 \mathrm{~m} / \mathrm{min}$ and $\mathrm{f}=0.2 \mathrm{~mm} / \mathrm{rev}$. The FFT is performed on all the length of the signal. This kind of signal treatment cannot give the instant when a frequency is occurring. In this case, the idea was to know only the frequency.

For the spindle current, the level can be compared with other examples (average around $5.5 \mathrm{~A}$ ), while in frequency domain the results are changing. The global FFT shows the main frequency observed during this test is at $\sim 7500 \mathrm{~Hz}$. It may be explained by the fact that due to the increase flank wear, the torque values are also increasing, together with important torsional vibrations of system. The finite element analysis shows that these torsional vibrations appear around $6500 \mathrm{~Hz}$. The explanation of this frequency needs more studies for a higher accuracy.
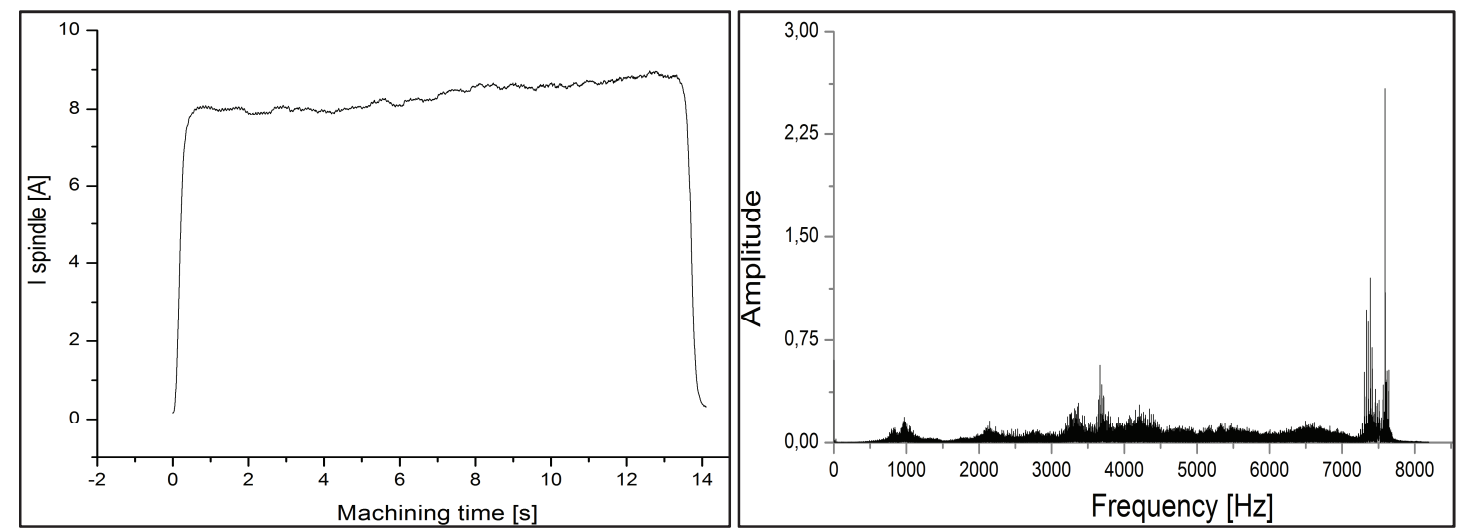

Figure 11. Spindle current evolution and global FFT

Another difference between these two zones is represented by the second hole, having as direct consequence the tool breakage. The recorded signals indicate that the tool failure arrives immediately after the tool entrance in the material (Figure 12 - grey curve).

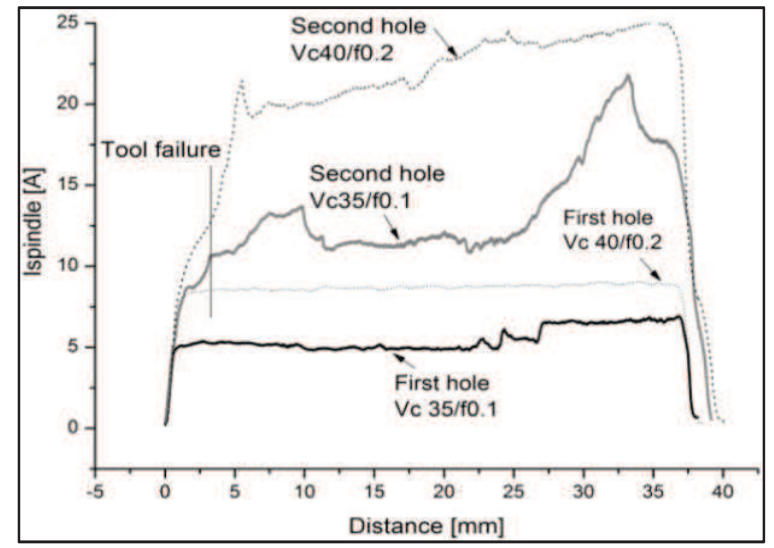

Figure 12. Spindle current evolution at high cutting speeds 


\subsection{Notch}

In the next part, a characteristic test for the notch apparition will be analyzed. Figure 13 presents the results in terms of monitoring signals for the cutting conditions $\mathrm{Vc}=22 \mathrm{~m} / \mathrm{min}$ and $\mathrm{f}=0.1 \mathrm{~mm} / \mathrm{rev}$. For these kind of tests, the evolution of the spindle current and cutting forces follows the same typology described by Nouari [11]. When a notch is produced, the surface contact between the tool and work piece is increasing. The spindle current and dynamometers signals highlight this failure mode by a sudden increasing in amplitude (Figure 13a, c). Again, the spindle current and the torque present the same typology. More interesting is the time-frequency diagram. The considerations made until now for the other tests are still right. The first part of drilling is identified by the same frequency evolution, dynamometer Kistler $(1000 \mathrm{~Hz})$ and second mode of the system $(1350 \mathrm{~Hz})$. In this example, around 10 seconds, a stable zone of machining exists and is verified by the fourth mode of system $(1950 \mathrm{~Hz})$. In fact, the notch induces disequilibrium between the two teeth and an important effort over the red direction. This excitation will generate a frequency change and will highlight the second vibration mode of the system $\sim 1350 \mathrm{~Hz}$. In the same time, Kistler dynamometer will respond with the $\sim 1000 \mathrm{~Hz}$. As the efforts and the torque increase, another peak of frequency will have high amplitude $(\sim 6000 \mathrm{~Hz})$, which is the natural frequency of Kistler dynamometer along thrust force. All these frequencies are illustrated with black ellipse on the Figure 13b. Further, the tool geometry is redone and the power consumption is stabilizing.

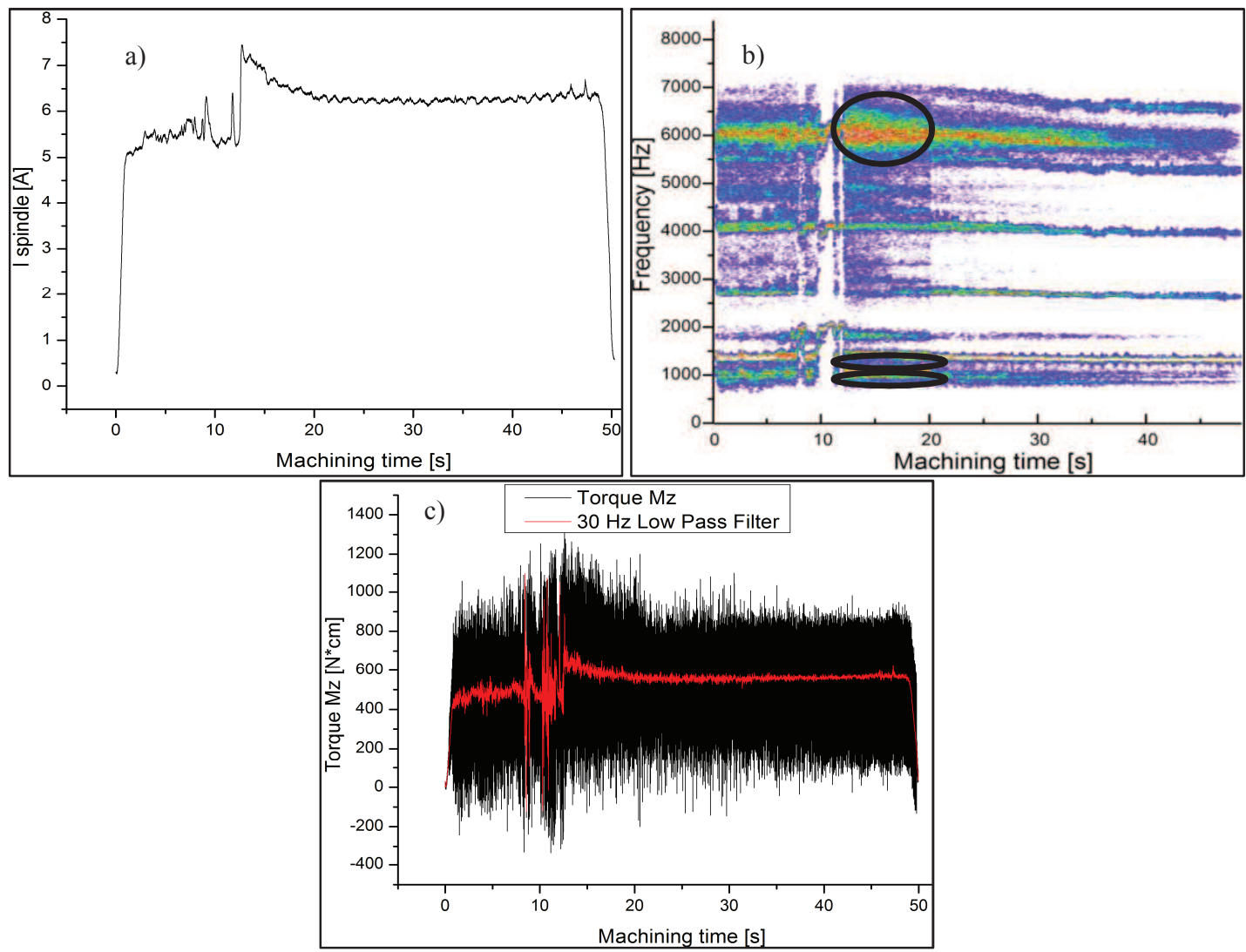

Figure 13. a) Spindle current; b) Time-frequency diagram; c) Torque Mz

It has to be mentioned that for this tool failure mode, analyses are more difficult to perform. For example, when the feedrate increase from $0,1 \mathrm{~mm} / \mathrm{rev}$ to another value, the tool workpiece contact can modify the dynamic characteristics [17].

\subsection{Tool breakage}

Finally, the tests offer the third failure mode, which is the catastrophic wear. The TCM is easier for this case and it does suppose a monitoring using the spindle current. All drillings show that when the spindle current exceeds 12 A, the tool breakage occurs. Further, an example for the tool 
breakage will be presented. Due to the high forces generated during these tests, most of accelerometer signals were overloaded and are not used in this work. Figure 14 illustrates the signal evolution when a tool breakage arrives. The cutting conditions are $\mathrm{Vc}=30 \mathrm{~m} / \mathrm{min}$ and $\mathrm{f}=0.15$ $\mathrm{mm} / \mathrm{rev}$.

A normal machining is followed by a $50 \%$ increase in terms of cutting forces. But, in this situation, the cutting action is replaced by extrusion and this typology is normal. Regarding the frequency evolution, the situation is more complex. Figure $14 \mathrm{~b}$ shows the frequency evolution over the time. Due to important values of the efforts and torque generated, several frequencies are highlighted after the tool breakage (after 18s - Figure 14b). The dynamometer and the tool are responding with the $1000 \mathrm{~Hz}, 1350 \mathrm{~Hz}, 6000 \mathrm{~Hz}$ and their harmonics. More interesting is the first part of the drilling. The results indicates a frequency around $7500 \mathrm{~Hz}$. It is the same frequency found for high cutting speeds.
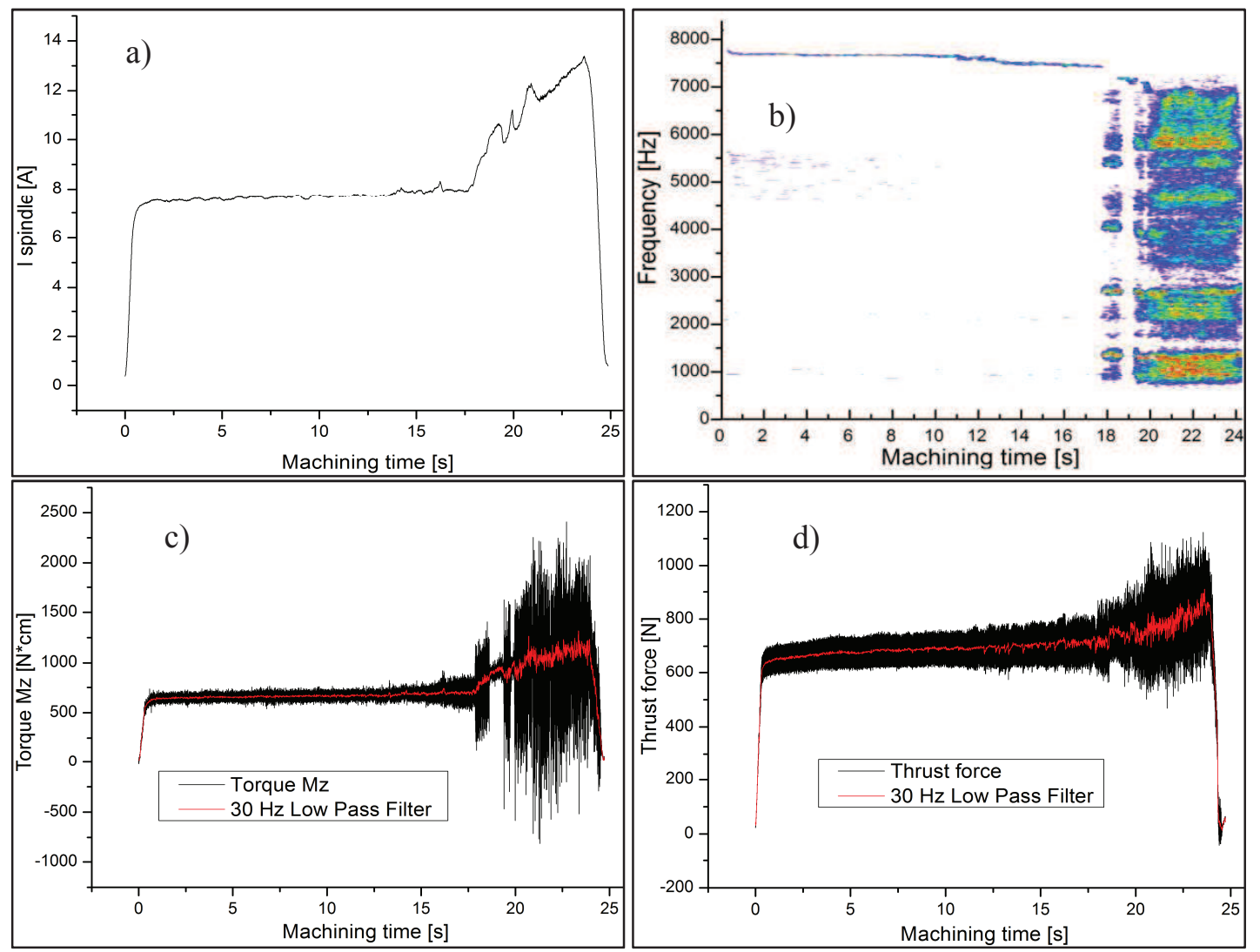

Figure 14. a) Spindle current; b) Time-frequency diagram; c) Torque Mz; d) Thrust force

\subsection{Monitoring strategy}

A future tool monitoring strategy may be proposed around the results presented in this study. In the Figure 15 the strategy monitoring is presented. It is based on the spindle current and the accelerometers measurements, which are recorded by an acquisition system. Further, the signals are treated and a decision is taken considering different outputs. For example, when a slowly increase of spindle current (between two values defined before) is detected and in the same time the band pass results shows the apparition of one particular frequency, this analyze may be associated to a $\mathrm{Vb}$ higher than $0.06 \mathrm{~mm}$. The values corresponding to the different "Band Pass" and " $\mathrm{x}$-values" for the spindle current have to be defined as a function of machining context. In the same, in the Figure 15 , the real values are not disclosed due to the facts that are used in industrial applications.

For the implementation of this strategy, it is necessary to perform a signal treatment according to:

- Spindle current

- Sampling rate $-250 \mathrm{~Hz}$ 
- I - different values defined as a function of machining context

- Maximum value

- Accelerometers

○ Sampling rate $16000 \mathrm{~Hz}$

- Band pass filters applied on interesting frequencies

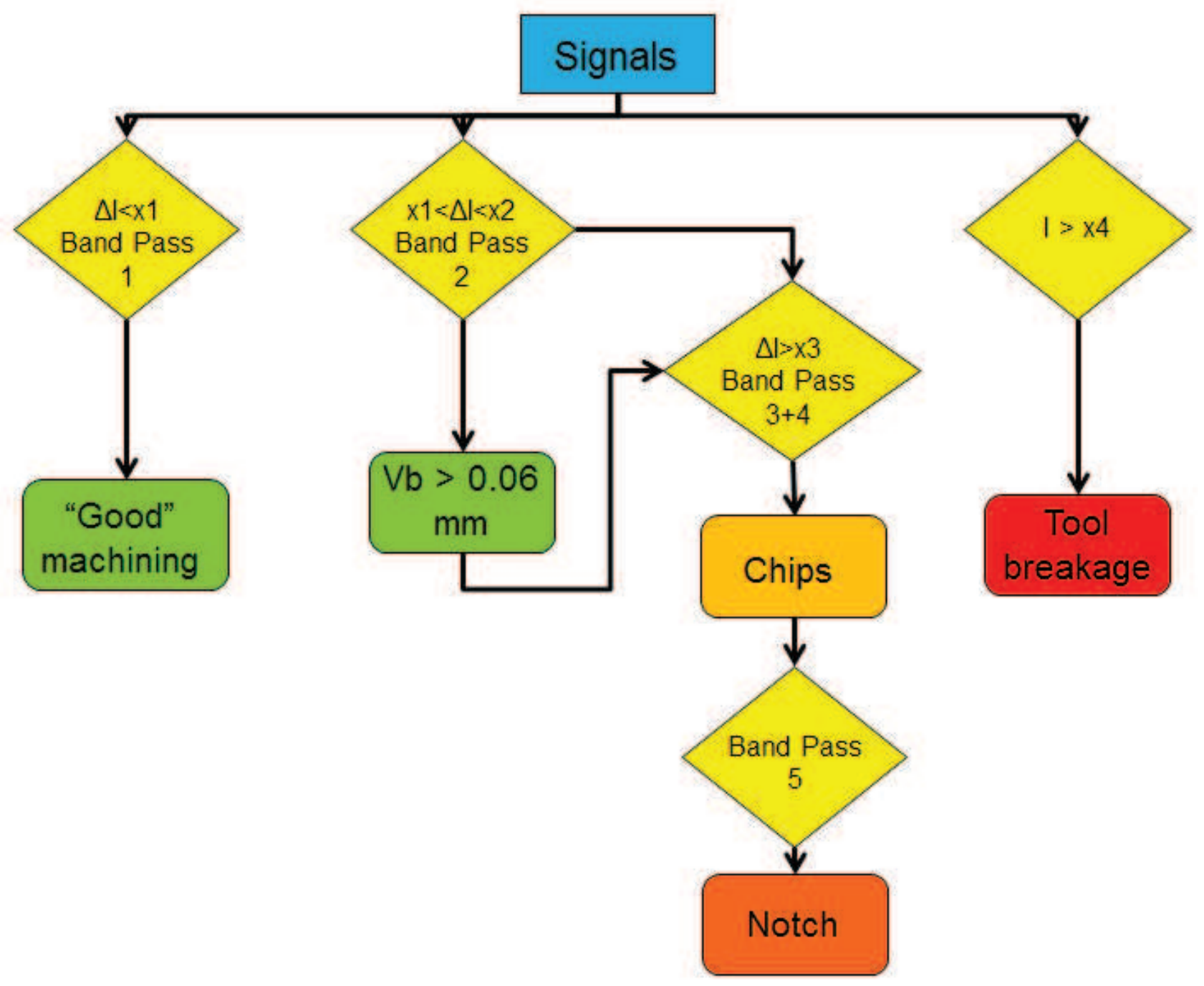

Figure 15: Monitoring strategy

\section{Conclusions}

The purpose of this study is to present a monitoring strategy able to detect the tool condition and possible machining disturbances. The experimental campaign shows the different failure modes and the relations with the recorded signals. All the trials were monitored with a four components dynamometer, three accelerometers and the signals extract from the machine-tool NC.

The results show that flank wear and notch are the main failure modes. The flank wear is slowly increasing even after 10 holes. The notch surface increase with higher feedrate too important cutting forces leads to the tool breakage. One important result is the cartography of failure modes. But, it might change due to the variability on the quality of manufactured tools. 
In terms of tool condition monitoring, promising results could be obtained by associating the flank wear/notch with the spindle current, accelerometers or thrust force. A monitoring strategy based just on spindle current is not possible due to different phenomena that overlap. Considering a mean value for this signal, it is impossible to make the difference between a chips evacuation problem and a notch wear. These two phenomena present the same sudden increase, around $30 \%$. Nevertheless, the spindle current signal issue from machine $\mathrm{NC}$ has the advantage to be already filtered and easy to implement in a process monitoring technique for industrial partners, together with the accelerometers.

The following conclusions can be done:

- Identification of failure modes in drilling of Udimet $720^{\circledR}$ was done;

- Detection of machining disturbances (such as chips evacuation) can be done using the spindle current and the accelerometers;

- The monitoring of third natural mode of system can give information about the flank wear level (higher than $0.06 \mathrm{~mm}$ );

- TCM is possible with two physical measurements which are easy to implement in industrial area: spindle current and accelerometers.

All these information were gathered into a first level of a monitoring strategy. Of course, more analyses have to be performed in order to make reliable this proposal.

The futures researches have to be focused more on accelerometers in order to precise the others frequencies (for example $7500 \mathrm{~Hz}$ ). The use of statistical techniques and some special signal treatments (e.g. Hilbert-Huang Transform, Wavelet Transform, etc.) should be another direction of interests. Their results will permit to increase the reliability of tool monitoring in Udimet $720^{\circledR}$ drilling and the implementation in industrial context.

\section{Acknowledgments}

The research leading to these results has received funding from the European Community's Seventh framework Programme (FP7/2007-2011) under grant agreement number 213855.

\section{References}

[1] E.O. Ezugwu, Key improvements in the machining of difficult-to-cut aerospace superalloys, International Journal of Machine Tools and Manufacture, 45 (2005), 1353-1367.

[2] A.R.C. Sharman, A. Amarasinghe, K. Ridgway, Tool life and surface integrity aspects when drilling and hole making in Inconel 718, Journal of materials processing technology, 200 (2008), $424-432$.

[3] A. Devillez, F. Schneider, S. Dominiak, D. Dudzinski, D. Larrouquere, Cutting forces and wear in dry machining of Inconel 718 with coated carbide tools, Wear, 262 (2007), 931 - 942.

[4] Y.C. Chen, Y.S. Liao, Study on wear mechanisms in drilling of Inconel 718 superalloy, Journal of Materials Processing Technology, 140 (2003), 269 - 273.

[5] E. Jantunen, A summary of methods applied to tool condition monitoring in drilling, International Journal of Machine Tools and Manufacture, 42 (2002), 997- 1010.

[6] D. Axinte, N. Gindy, Assessment of the effectiveness of a spindle power signal for tool condition monitoring in machining processes, International Journal of Production Research, 42 (2004), $2679-2691$.

[7] I. Abu-Mahfouz, Drilling wear detection and classification using vibration signals and artificial neural network, International Journal of Machine Tools and Manufacture, 43 (2003), 707 720.

[8] T. Kalvoda, Y.R Hwang, A cutter tool monitoring in machining process using Hilbert-Huang transform, International Journal of Machine Tools and Manufacture, 50 (2010), 495 - 501. 
[9] V.Dutilh, G.Dessein, J. Alexis, G.Perrin, Links between machining parameters and surface integrity in drilling Ni-superalloy, Advanced Materials Research, 112 (2010), 171-178.

[10] V.Dutilh, A.Popa, G. Dessein J. Alexis, G. Perrin, Impact of disturbed drilling conditions on the surface integrity of a Nickel-base superalloy, 7th CIRP Int. Conference on Intelligent Computation in Manufacturing Engineering - CIRP ICME '10, 23-25 June, Capri, Italy, ISBN 978-88-95028-65-1

[11] M.Nouari, M. Calamaz and F.Girot, " Wear mechanisms of cutting tools used in the dry machining of the aeronautic titanium alloy, Ti-6Al-4V," Comptes Rendus Mécanique, vol. 336 (2008), pp. 772-781.

[12] P.E Debard, B. Coulon, N. Batista, A description of a statistical approach for determination of relevant criteria on monitored milling tool life trials of Inconel 718, Intercut Conference, Cluny-France, 2010.

[13] D’Addona, D., Simeone, A., Teti, R., 2010, Neural Network Model for Tool Wear Curve Reconstruction during Turning of Inconel 718, 7th CIRP Int. Conference on Intelligent Computation in Manufacturing Engineering - CIRP ICME '10, 23-25 June, Capri, Italy, ISBN 978-88-95028-65-1

[14] M. Rancic, J-P Costes, G. Poulachon, Tool wear investigation: behavior in continuous trials vs. divided wear trials, 7th CIRP Int. Conference on Intelligent Computation in Manufacturing Engineering - CIRP ICME ‘10, 23-25 June, Capri, Italy, ISBN 978-88-95028-65-1

[15] N. Corduana, T. Himbart, G. Poulachon, M. Dessoly, M. Lambertin, J. Vigneau, B. Payoux Wear mechanisms of new tool materials for ti-6ai-4v high performance machining, CIRP Annals - Manufacturing Technology, 52, Issue 1, 2003, 73- 76.

[16] C.F. Bisu, P. Darnis, A. Gerard, J.Y. K'Nevez, Displacement analysis of self-excited vibrations in turning, International Journal of Advanced Manufacturing Technology, 44 (2009), $1-16$.

[17] T.Wehbe, A study by Image Stereo Correlation of thin part vibration during machining, Phd thesis, 2010, Institut National Polytechnique de Toulouse. 